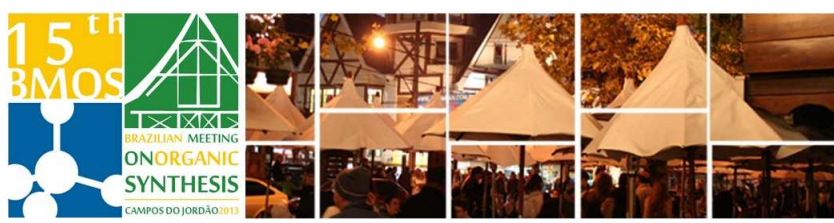

\title{
Discovery and synthesis of a new analogues of the cyclopenta[b]indoles as tubulin polymerization inhibitors
}

\author{
Fernandes, D. C. (PG) ${ }^{1}$, Santos, R. N. S. $(P G)^{2}$, Júnior, M. T. R (PQ) ${ }^{1}$, Andricopulo, A. \\ D. $(P Q)^{2}$ and Coelho, F. $(P Q)^{1}$
}

1- Instituto de Química, Universidade Estadual de Campinas, CP 6154, 13083-970,Campinas-SP, Brazil, 2Laboratório de Química Medicinal e Computacional, Centro de Biotecnologia Molecular Estrutural, Instituto de Física de São Carlos, Universidade de São Paulo, 13560-970, São Carlos-SP, Brazil.

*daniaraf@gmail.com

Keywords: Morita-Baylis-Hillman adducts, tubulin, cyclopenta[b]indole

\section{INTRODUCTION}

Cancer is a disease characterized by rapid and abnormal cell division and migration of tumor cells to other body organs. The development of small molecule modulators that interfere with microtubule dynamics through of the interaction with the tubulin is a particularly valid approach in cancer chemotherapy ${ }^{1}$. Recently, the search for simpler polymerization inhibitors agents has renewed the interest in the development of colchicine analogs, sometimes discarded for their high toxicity. In this context, a series of substances synthesized from Morita-Baylis-Hillman adducts ${ }^{2}$ (258 compounds) was screened using molecular docking. Application of physico-chemical filters guided the selection of a focused collection of cyclopenta[b]indole derivatives as potential microtubule polymerization inhibitors. Therefore, to improve the interaction between the cyclopenta[b]indole skeleton and the residues of colchicine sites, new analogs of this compounds have been designed and synthesized.

\section{RESULTS AND DISCUSSION}

The general method used for the diastereoselective synthesis was based on MoritaBaylis-Hillman reaction and has been reported by our research group ${ }^{3}$ (Figure 1).
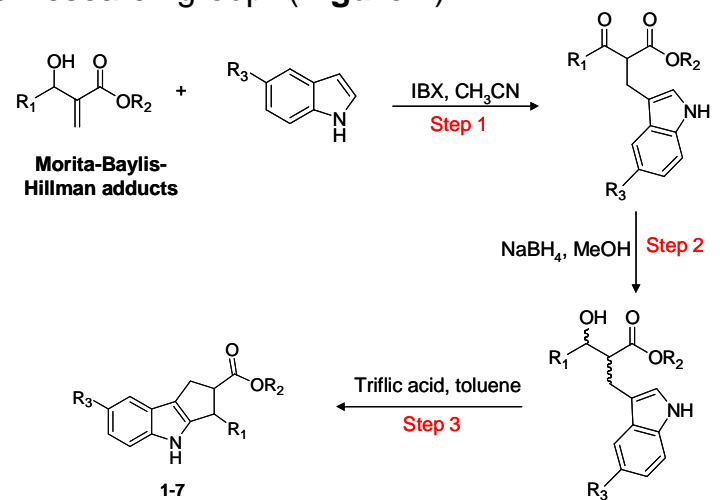

Figure 1. Synthesis of cyclopenta[b]indole derivatives 1-7.

The starting Morita-Baylis-Hillman adducts were first oxidized with 2-iodoxybenzoic acid followed by Michael addition to produce 1,3-dicarbonyl compounds, which were selectively reduced in the presence of $\mathrm{NaBH}_{4}$. For reaction development, the resulting alcohol was treated with trifluoromethanesulfonic acid (triflic acid) lead to the new cyclopenta[b]indoles derivatives (1-7) with an excellent diastereoselectivity (>99:1) (Figure 2).

These derivatives were designed and synthesized based on taking the quantitative inhibition $\mathrm{IC}_{50}$ and the possible molecular interactions with residues from the colchicine-binding site. This binding mode is mainly sustained by two hydrogen bonds: (i) between the carbonyl group of the ester substituent in position 2 of the cyclopenta[b]indole derivatives and the thiol group of the residue C241B and (ii) the hydroxyl group at position 5 of the cyclopenta[b]indole derivatives and the carbonyl group of the residue $\mathrm{V} 315 \mathrm{~B}$.

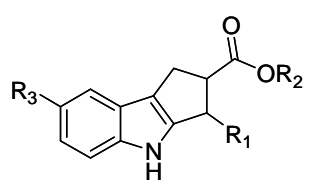

1- $\mathrm{R}_{1}=3,4,5-\mathrm{OCH}_{3}-\mathrm{Ph}, \mathrm{R}_{2}=\mathrm{CH}_{3}, \mathrm{R}_{3}=\mathrm{H}$ 2- $\mathrm{R}_{1}=3,4,5-\mathrm{OCH} 3-\mathrm{Ph}, \mathrm{R}_{2}=\mathrm{H}, \mathrm{R}_{3}=\mathrm{H}$

3- $\mathrm{R}_{1}=3,4-\mathrm{OCH}_{3}-\mathrm{Ph}, \mathrm{R}_{2}=\mathrm{CH}_{3}, \mathrm{R}_{3}=\mathrm{OBn}$ 4- $\mathrm{R}_{1}=3,4-\mathrm{OCH}_{3}-\mathrm{Ph}, \mathrm{R}_{2}=\mathrm{H}, \mathrm{R}_{3}=\mathrm{OBn}$ 5- $\mathrm{R}_{1}=3,4-\mathrm{OCH}_{3}-\mathrm{Ph}, \mathrm{R}_{2}=\mathrm{CH}_{3}, \mathrm{R}_{3}=\mathrm{OH}$ 6- $\mathrm{R}_{1}=$ pyperonyl, $\mathrm{R}_{2}=\mathrm{H}, \mathrm{R}_{3}=\mathrm{OBn}$ 7- $\mathrm{R}_{1}=$ pyperonyl, $\mathrm{R}_{2}=\mathrm{CH}_{3}, \mathrm{R}_{3}=\mathrm{OH}$

Figure 2. Chemical structures of cyclopenta[b]indoles derivatives.

The competitive assays against the colchicine binding site, molecular modeling studies and its effects on microtubule organization, cell migration and cell cytotoxic activity confirming the importance of the metoxy group for the inhibitory microtubule activity.

\section{CONCLUSION}

A modern approach to medicinal chemistry allowed the identification and the synthesis of a new series of tubulin modulators with anticancer activity. The studies led to the elucidation of the mechanism of action, revealing key molecular aspects involved in the interaction of these compounds with the target protein.

\section{ACKNOWLEDGEMENTS}

FAPESP, CNPq and CAPES.

\section{REFERENCES}

${ }^{1}$ Zhao, H. et al. Cancer Letters, 2012, 314, 54.

${ }^{2}$ Baylis, A. B.; Hillman, M. E. D. German Patent 2155113, 1972 (C.A.. 1972, 77, 34174q).

${ }^{3}$ Coelho, F. et al. Tetrahedron, 2002, 58, 7437. 